\title{
Structure and Topography Modifications of Treated AISI 316LN Stainless Steel Surfaces after Friction in Dry Sliding Contact by Case Hardening Process
}

\author{
M.Mamatha Gandhi ${ }^{*}$, Animesh Bain ${ }^{1}, P$ Rohith $^{1}$, R. Srilatha ${ }^{1}$, Ram Subbiah ${ }^{1}$ \\ ${ }^{1}$ Mechanical Engineering Department, Gokaraju Rangaraju Institute of Engineering \& Technology, Hyderabad, India
}

\begin{abstract}
Austenitic stainless is having corrosion resistance property, but certain mechanical applications require improved resistance to wear, inferior cavitation, susceptibility to sensitization. These steels have numerous favourable circumstances for great cryogenic - properties, anti-corrosion, and bio-compatibility. So these steels have a broad application in low temperature innovation, saltwater applications, nourishment industry, bio-medicine, petro-chemical handling, and so forth when alloyed with nitrogen, austenitic treated steels has a progressively steady austenite structure, better mechanical properties and better wear opposition, which has animated extraordinary enthusiasm for this exploration work. Many surface hardening techniques are available, the best surface modification technique is chosen for improved service performance. Surface engineering is a technique to alter the surface of a material by mechanical or microchemical method without affecting the material properties. The alterations are done on the surfaces subjected to the liquid nitriding process to produce a hardened surface. Chosen for this research workbased on their wide application, the wear behaviour of AISI 316LN stainless steels was investigated. Of the various surface hardening techniques available, nitriding is chosen, so that these nitrogen gets penetrated into the material, in which hard iron chromium nitrides are formed at the surface level. AISI $316 \mathrm{LN}$ specimens were subjected to salt bath nitriding process. The specimens were nitrided to 60 minutes, 120 minutes and 180 minutes respectively. The specimens were undergone with wear tests by standardized tribiological wear machine and finally the metallographic studies were made.
\end{abstract}

\section{Introduction}

In all the steel applications, a high surface hardness joined with protection from wear is required. Nitriding is one of the notable components for surface solidifying, in which Fe and other alloying components joined with nitrogen to frame nitrides. Be that as it may, for austenitic stainless steel types, the increment of carbon content, in certain temperature conditions, decides the precipitation of chromium carbides to the furthest reaches of the austenite grains and certainly, to diminish the protection from entomb crystalline erosion. So as to expel this, nitridization is done to expand the surface hardness without influencing the property of a material. In the event of austenitic stainless steels, the development of chromium nitrides induces the decrease in the chromium in the combination which is the principle liable for protection against corrosion.

Salt shower nitriding process is an elective procedure of gas nitriding process, which would deliver

*Corresponding Author: mamatha.mannaragudi@gmail.com increasingly uniform and better metallurgical framed case depth. A salt solution would satisfy the consistency prerequisite through surface contact of the salt solution to the steel. The profundity and the nature of the case would be controlled by the composition of the salt arrangement. A warmth source would be vital to drive the nitrogen into the steel surface. Salt shower nitriding employments the softening of salt containing wealthy nitrogen source. At the point when warm is connected from either internal or exterior source, the salt dissolves and liberates nitrogen into the steel for scattering. At this point when the steel work piece is brought into the salt shower and warmed up to a temperature within the fluid salt, so that controlled measures of nitrogen are released to diffuse into the surface. The salt shower nitriding strategy is favoured for its low capital speculation than gas nitriding. Casedelivering salt solution may change as for manufactures; however they are fundamentally made with sodium and potassium cyanides. The common salt mixture consists 55 to $65 \%$ sodium salts, 35 to $45 \%$ potassium salt is liquefied at 823 to $890 \mathrm{k}$. During the liquefying time, a cover is placed on the top to avoid splashing or blast ofthe salt, except if the hardware is 
totally hooded and vented. Amid the liquefying time, a cover is put on the best to dodge sprinkling or impact of the salt, but in the event that the equipment is completely hooded and vented. Stainless steels resistance to erosion and recoloring, low maintenance, relative in costs and recognizable gloss make it an perfect base material for a host of commercial applications $[12,13]$. The utilization of stainless steels is compared with that of carbon steels but shows a unfaltering development, in differentiate to the constructional steels and their properties in numerous cases moderately new to the designer $[14,15]$.

\section{Experimental Details}

\subsection{Specimen Preparation}

Chosen for the research work, the material is AISI 316 LN Austenitic stainless steel fabric and the composition is appeared in Table 1, having the measurements of breadth $12 \mathrm{~mm}$, length of $40 \mathrm{~mm}$ and the plate having the measurements of $150 \mathrm{~mm}$ breadth, $10 \mathrm{~mm}$ thickness as appeared within the Fig 1. The composition was found to be carbon $0.03 \%$, Manganese $1.57 \%$, silicon $0.7 \%$, Phosphorus $0.45 \%$, chromium $18 \%$ max, sulphur $0.03 \%$, Nickel 14\% max, Molybdenum 3\%, remaining Fe. The cut tests are checked to be liberated from any edge burrs or surface dirtying impacts along the total surface. Any surface awfulness or surface burrs encompassed amid the cutting are cleared by scouring them against different evaluations of emery paper [17]. The tests surface ought to essentially be from surface sullying impacts like oil, soil, etc and can be evacuated by cleaning the cases in $\mathrm{CH} 3$ ) $2 \mathrm{CO}$ course of action some time recently driving the wear tests [21-23].

\subsection{Treatments Done}

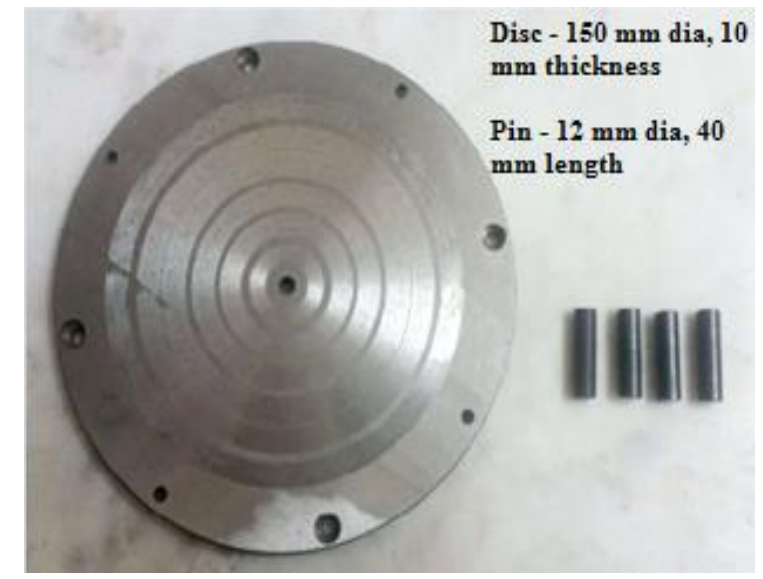

Fig 1. AISI 316LN Specimen Dimensions

The ordinary commercial shower for nitriding is composed of $60-70 \%$ with a blend of $\mathrm{NaCN}$, $\mathrm{NaCO} 3$ and $\mathrm{NaCNO}$ appeared within the Fig 2. The bathused in fluid weight nitriding works with a cyanide substance of 30 to $35 \%$ and acyanate substance of 15 to
$20 \%$. The fluid shower at first matured at a temperature of $480^{\circ} \mathrm{C}$ as shown in Fig 3 to extend the nitrogen substance and parts are immersed within the fluid for 60 minutes, 120 minutes and 180 minutes individually. Salt shower nitriding prepare is an elective prepare of other nitriding process because it is commercially accessible, which would deliver more uniform and way better metallurgical shaped case. A fluid would fulfil the consistency prerequisite through surface contact of the liquid to the steel. The profundity and the quality of the case would be decided by the composition of the fluid. Salt shower nitriding utilizes the softening of salt containing wealthy nitrogen source[18].

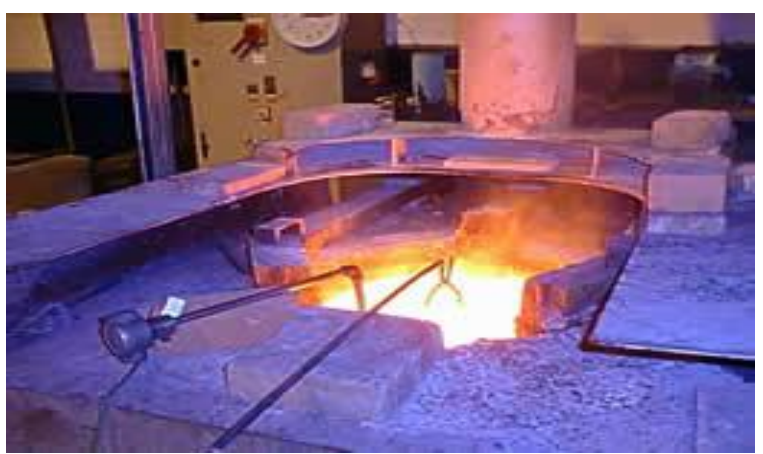

Fig 2. Salt Bath Nitriding Furnace Used

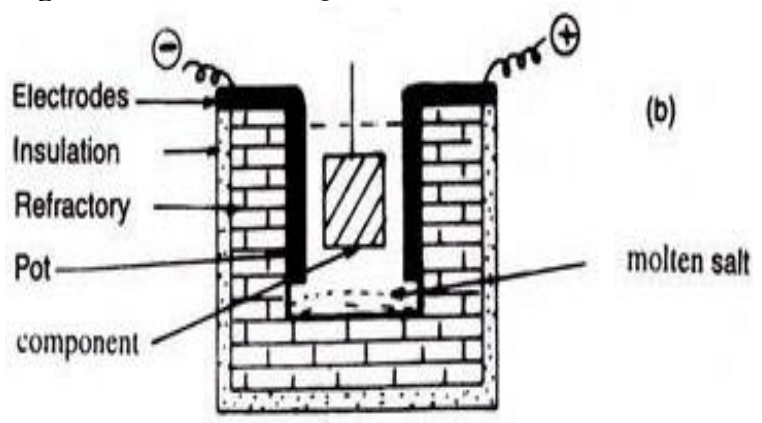

Fig 3. Layout of Salt Bath Nitriding Process

When warm is connected from either inside orexternal source, the salt dissolves and frees nitrogen into the steel for diffusion. When the steel work piece is presented into the salt shower and warmed up to a temperature within the liquid salt, controlled sums of nitrogen are discharged to diffuse into the surface. Liquid salts in customary showers ought to be matured by being held at 838 to $868 \mathrm{k}$ for at slightest $12 \mathrm{hrs}$, and no work should be put within the shower amid the agingtreatment [19]. The proportion of cyanide substance to cyanate substance shifts with the salt bath process and the composition of the shower. Salt shower nitrided components exhibit fabulous sliding and running in properties as well as more prominent wear resistance. This nitriding progresses wear resistance, lubricity, and weakness quality and corrosion resistance as a result of the nearness of press nitride compounds shaped at the surface in expansion to a zone of diffused nitrogen in strong arrangement with the base fabric [20]. 


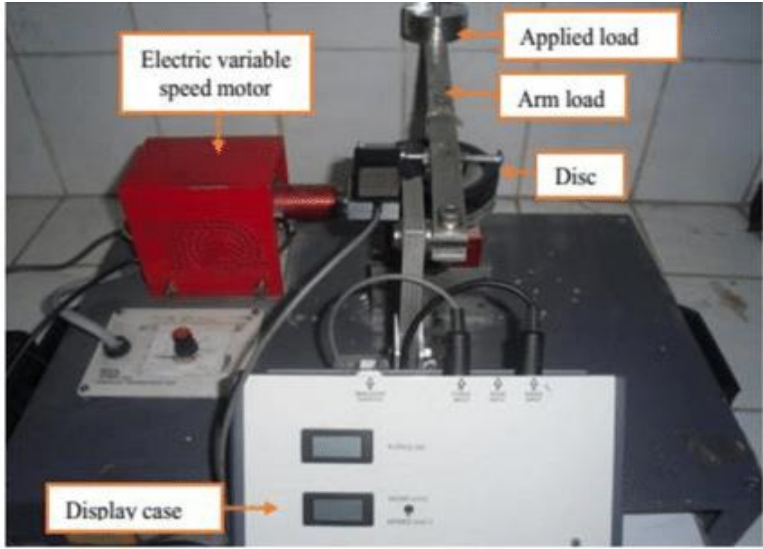

Fig 4. Pin on Disc Machine Used

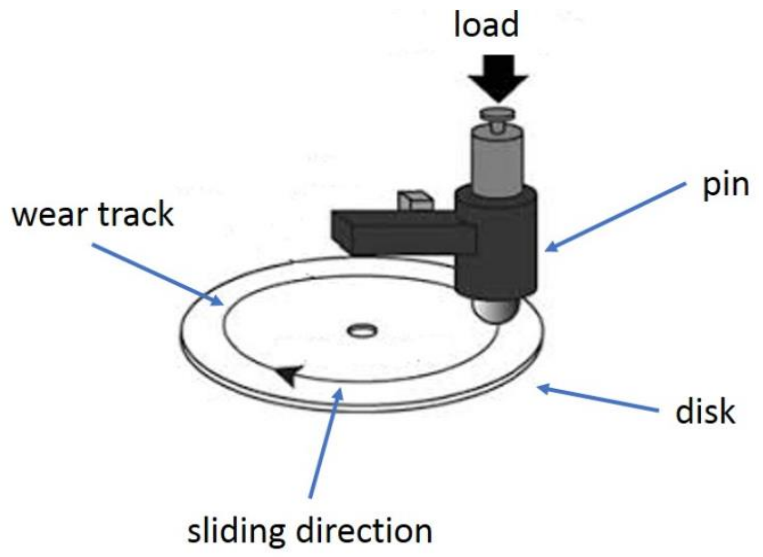

Fig 5. Layout of Wear Test

\subsection{Smaller scale Hardness Estimations}

Vickers hardness estimations were made to assess the effect of the nitrogen on the shallow hardness of The nitrided tests. The hardness at the surface level which were assessed for all the tests. For the untreated base metal the hardness was found to be as $327 \mathrm{Hv}$. The extension in hardness was seen to be twice more noteworthy than the untreated tests. The hardness tests were performed by applying a stack of 100 grams for 15 seconds [12-15]. The development within the hardness at the surface layer of the total nitrided illustration is since of the advancement of compound and scattering zone with collections of nitrides named asCrN, Cr2N, Fe2-3N, Fe4N. The hardness was found to be $719 \mathrm{Hv}, 841 \mathrm{Hv}, 906 \mathrm{Hvfor}$ the tests nitrided at 60 min, $120 \mathrm{~min}$ and $240 \mathrm{~min}$ respectively.

\section{Results \& Discussions}

From the scanning electron microscope analysis, the wear difference was identified between the untreated specimen and nitrided specimen. The untreated samples were found to have more peel of material as they have low hardness and strength. Micro cracks and holes were found in untreated sample shown in the Fig 6 . The action of the presence of nitrogen improves the wear behaviour and the stainless character was maintained. The ion implanted specimens showed a significant increase in the hardness value with compressive residual stress and micro distortions in the high nitrogen containing layer. The peels of fabric were found to be moot when compared to untreated test appeared within the Fig 7. The nitrogen implantation process induces the arrangement of the metastable stage. This stage come about from the incorporation of nitrogen into the interstitial positions of the face centered cubic structure of stainless steels.

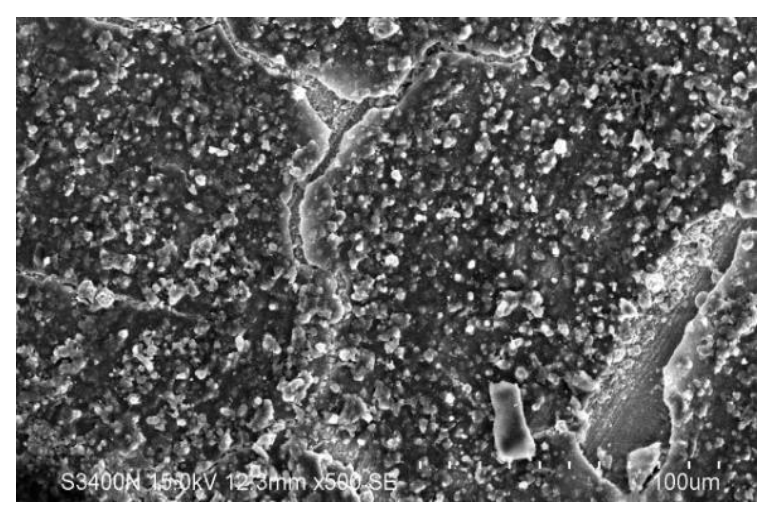

Fig 6. Untreated AISI 316 LN Sample SEM Image

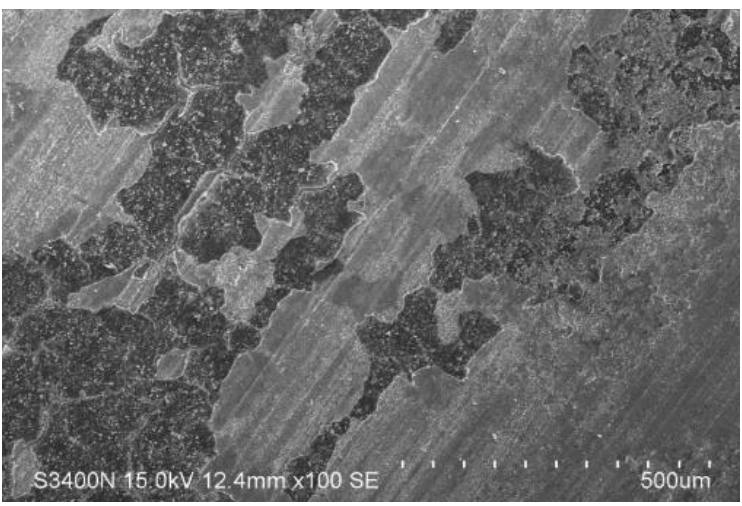

Fig 7. SEM Image of 60 Minutes Nitrided sample

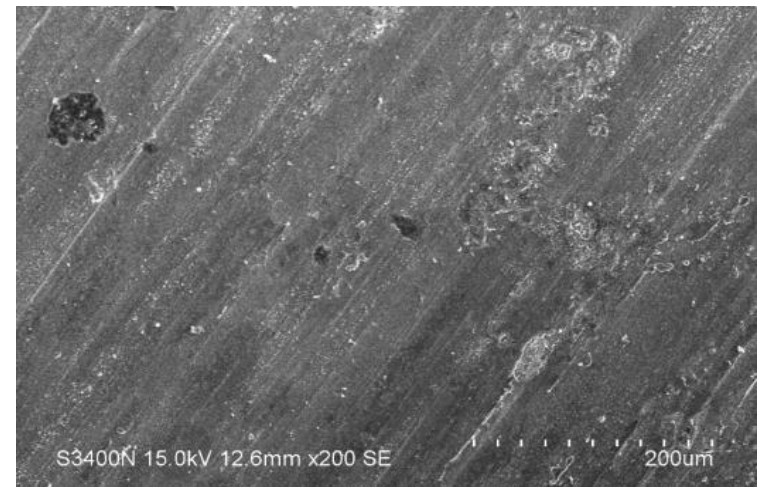

Fig 8.SEM Image of 120 Minutes Nitrided sample

Nitrogen joining from the perspectives of mixture component, super immersion and energy is considered. The structural refinement, driving to nano crystallization [16] and stage transformations, consisting of austenitization and amorphization, are sketched out. Especially from the Fig 8, it was noted that nitrogen heighten grain refinement and continues 
to ferrite to austenite phase transformation and amorphization during mechanical alloying.

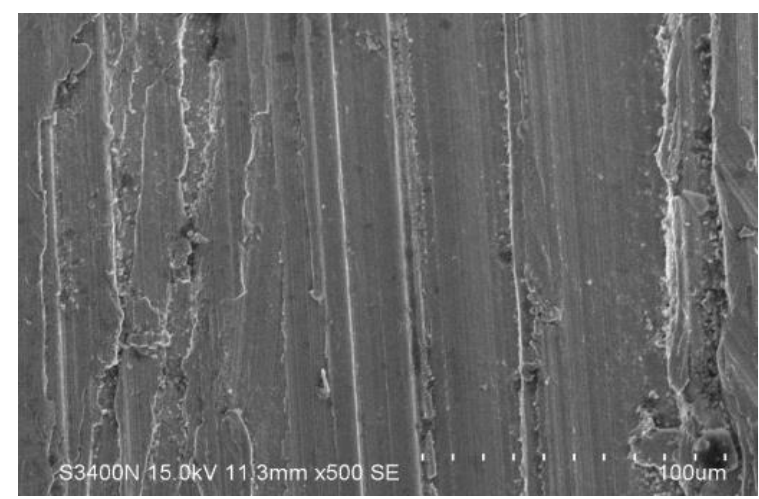

Fig 9. SEM Image of 180 Minutes Nitrided sample

The sub surface modifications induced by nitrogen ion implantation revealed that the surface hardness reached up to $906 \mathrm{H}_{\mathrm{V}}$. From the Fig 9, it was observed that nitriding induced phases containing the mixture of iron and nitrogen compounds remain most important. Liquid nitriding of stainless steels at temperature about $480^{\circ} \mathrm{C}$ showed nitrogen enriched layers with higher nitrogen content leading to a significant increase in the hardness.

\section{Conclusion}

The effect of sliding wear behaviour of austenitic stainless steels of grade AISI 316LN were studied and reported that the sliding wear affected there passivation by increasing the level of expanded austenite phase and greatly influenced by the increase in formation of Chromium Nitride It was reported salt bath nitriding improves the wear resistance of austenitic stainless steel sort AISI 316LN. The hardness were extended from $328 \mathrm{Hv}$ to $906 \mathrm{Hv}$, appeared up to be uniform and formed by two sub layers. The upgrade of the surface layer with nitrogen, up to a temperature of $4800 \mathrm{C}$ brought almost in basic wear resistance and it has been advanced. The micro structures and the wear properties of austenitic stainless steels have been investigated and the wear resistance of stainless steels in watery environment was credited to the arrangement of detached film, which was amazingly a lean layer in which chromium particles are improved as oxide orhydroxide. The inactive film was conceivable to be more defensive by different added substances such as molybdenum and nitrogen.

\section{References:}

1. J. Jin, T. Shao, Surf. Coat.Technol. 344 (2018).

2. D. Moses, G. Haider, J. Henshaw, Eng. Fail. Anal.100 (2019).

3. R.V. Pushkarev, N.I. Fainer, H. Katsui, Mater.Des.137 (2018).
4. T.S. Hummelshøj, T.L. Christiansen, M.A.J. Somers, Scripta Mater. 63(7) (2010).

5. J.G. Kang, N. Lin, Y. Jiang, Materials Science and Engineering of Powder Metallurgy 22 (1) (2017).

6. Baloji, D., Anil, K., Satyanarayana, K., Singh, S. K., \& Naik, M. T. Material Today 18, 4475-4481. (2019).

7. L. An, Q. Ma, J. Jiangang, Hot Working Technology40 (22) (2011).

8. A.P. García-Mendoza, G. Vargas-Gutiérrez, J. López-Cuevas, Surf. Coat.Tech. 353 (2018).

9. W. Tian, S. Li, J. Liu, Chin. J. Aeronaut. 30 (5) (2017).

10. R.V. Pushkarev, N.I. Fainer, H. Katsui, Mater.Des.137 (2018).

11. Suresh Kumar Tummala, Dhasharatha G, E3S Web of Conferences 87, 01030 (2019).

12. J.W. Zhang, L.T. Lu, K. Shiozawa, W.N. Zhou, W.H. Zhang, Int. J. Fatigue 33(7) (2011).

13. C.Anandhan, William Grips, V.EzlilSelvi 201 (2007).

14. C.Dawes, D.F.Tranter, Heat Treatment Materials, 4 (1982)

15. C.H.Hsu, C.K.Lin, K.H.Huang, K.L.Ou, Surface Coatings and Technology, 88 (2012).

16. Baloji, D., Anil, K., Satyanarayana, K., Singh, S. K., \& Naik, M. T. Materials Today: Proceedings 18, 4475-4481. (2019)

17. Tummala Suresh Kumar, Kosaraju Satyanarayana, Materials Today: Proceeding, 26(2020).

18. P. Sharma, A. Dhawan, S.K. Sharma, J. NonCryst. Solids 511 (2019).

19. H. Shen, L. Wang, Surf. Coat.Technol. 378 (2019).

20. C.S.Stawstorm, M.Hillert, Journal of Iron andSteel Institute, 207 (1999)

21. Md.Sumair Ur Rahman, L.Jayahari, Materials Today: Proceedings, E 5, 3(2018)

22. L.Jayahari, B.Balunaik, A.Kumar Gupta, S.K.Singh, Materials Today:Proceedings, E 2, 4 (2015)

23. Ratna Deepika M, Satyanarayana.K, Arul Raj K, Sateesh.N, Materials Today: Proceedings, E5, 9 (2018). 